\title{
A construção sócio-religiosa, política e cultural da mulher brasileira: do patriarcado colonial a contemporaneidade
}

\author{
Vicente Gregorio de Sousa Filho* \\ Conceição de Maria de Oliveira Miranda** \\ Antonio Michel de Jesus de Oliveira Miranda*** \\ Geisa Hupp Fernandes Lacerda $* * * *$
}

\section{RESUMO}

Objetivamos, a partir da noção de mulher, construída pelo imaginário social brasileiro, identificar a construção sócio-religiosa, política e cultural desta mulher na história do Brasil, compreendendo seus diferentes papeis sociais ao longo da história; e, analisar, à luz da noção patriarcalista, como a mulher se assumiu nesse processo histórico brasileiro, onde, a partir de uma pesquisa bibliográfica e qualitativa, corroborados com autores como Del Priore (2005), Lopes (2003), Freyre (2006), D’Incao (2008) e documentos da Igreja, percebemos a mulher como sujeito de sua própria história e, que mesmo em meio ao patriarcalismo, com suas lutas e vozes, elas emergem e se assumem igualitariamente nos mais distintos contextos sociais.

Palavras-chave: mulher; Brasil; patriarcalismo; construção social.

* Doutor em Teologia - Faculdades EST. Professor D.E. IFMA. vicente6@bol.com.br

** Bacharel em Teologia - UFPI. Professora Ed. Básica - SEDUC -Parnaíba - PI. ceicamiranda@gmail.com

*** Mestrando em Ciências das Religiões - FUV - ES. Professor Ed. Básica - SEMED Tutoia-MA; SEMED - Buriti dos Lopes-PI. educadormichel@gmail.com

**** Mestranda em Ciências das Religiões - FUV - ES. Professora de Pedagogia - UNESC, Serra campus II. ge.laceda@hotmail.com 


\section{THE SOCIO-RELIGIOUS, POLITICAL, AND CULTURAL CONSTRUCTION OF BRAZILIAN WOMAN: FROM THE COLONIAL PATRIARCHY TO CONTEMPORARY}

\section{ABSTRACT}

Based on the notion of woman, constructed by the Brazilian social imagination, we aim to identify the socio-religious, political and cultural construction of this woman in the history of Brazil, understanding her different social roles throughout history; and to analyze, in the light of the patriarchal notion, how the woman assumed in this Brazilian historical process, where, based on a bibliographical and qualitative research, corroborated with authors such as Del Priore (2005), Freyre (2006), D'Incao (2008) and documents of the Church, we perceive the woman as subject of her own history and that even in the midst of patriarchalism, with their struggles and voices, they emerge and assume themselves equally in the most distinct social contexts.

Keywords: women; Brazil; patriarchy; social construction.

\section{Introdução}

As mulheres atuais ocupam os mais distintos cargos profissionais, muito embora há muito ainda o que se discutir sobre a igualdade de salários. Ocupam ainda, com bastante expressividade, vozes perante à distintos contextos e instituições sociais como no matrimônio, na escola, na política, na igreja, dentre outros.

O cenário expressivo e supostamente igualitário de hoje, vivenciado pela mulher, ainda carrega consigo marcas de um passado não tão distante, onde mulheres lutaram por seus direitos.

Mulheres estadunidenses, mexicanas, europeias, brasileiras, dentre outras. Todas mulheres que carregam culturas diferentes e destas culturas, diferentes maneiras de entender o feminino. $\mathrm{O}$ ideário do feminino é uma construção social. E refletir sobre esta construção aqui no Brasil, pode evidenciar inúmeras mulheres e suas conquistas, bem como sua emancipação ao longo da história brasileira.

A mulher e o homem, juntos, são primordiais para a manutenção de uma sociedade justa e igualitária. Mas para isso, é preciso uma complementariedade e não uma disparidade, muito embora existam 
singularidades que os tornam, específicos enquanto animais, humanos e sujeitos de sua própria história.

Diante deste contexto nos emerge uma inquietude: de qual maneira a noção de mulher foi construída pelo imaginário social brasileiro?

Para irmos em busca deste desvelamento, delimitamos os seguintes objetivos para este trabalho: Geral: identificar a construção sócio-religiosa, política e cultural da mulher na história do Brasil. E específicos: compreender os diferentes papeis sociais da mulher brasileira ao longo da história; analisar, à luz da noção patriarcalista, como a mulher se assumiu no processo histórico brasileiro, desde o período da colonização portuguesa até os dias atuais.

Neste trabalho nos propusemos a uma análise histórico-bibliográfica e qualitativa da construção do feminino, a fim de evidenciar os desvelamentos sociais, as conquistas, os diretos e deveres, os quais ao longo da história brasileira, as mulheres vêm se tornando sujeitos de sua própria história.

Nossa empreitada se justifica pois, ao buscarmos destacar nesta pesquisa o rompimento com a submissão imposta pelo patriarcalismo desde o colonialismo, a mulher tem conseguido alcançar seu espaço.

\section{Brasil Colônia, Origens da Repressão Feminina}

A mulher no Brasil Colonial tinha uma vida de reclusão voltada somente para o espaço doméstico. Ela deveria ser obediente, sobretudo às leis do Estado e da Igreja. A imagem da mulher nesta época estava relacionada àquela que cometeu o pecado original, Eva. Todas as mulheres estavam condenadas a pagar pelo erro de Eva, conforme Araújo (2008, p. 46): “Já que a mulher partilhava da essência de Eva, tinha que ser permanentemente controlada". Esse controle era realizado pelos homens da família (os pais e irmãos mais velhos, depois o marido), e tinha por objetivo levar as moças a ter um comportamento de acordo com os costumes e a moral da época, principalmente no tangente à sexualidade.

Havia uma preocupação muito grande por parte das mães com o despertar da sexualidade das meninas, pois a partir do momento em que estas menstruassem pela primeira vez, estariam aptas ao casamento. A Igreja recomendava casar as meninas aos doze anos de idade, e 
os meninos com 14 ou 15 anos. Os pais tinham uma preocupação em casar as filhas muito cedo, pois temiam que estas se "desvirtuassem", então logo as estragavam ao controle dos maridos. Desta feita, "[...] era compreensível, portanto a inquietação dos pais quando a menina de 14 ou 15 anos ainda não se casara, ou melhor, quando não haviam conseguido marido para ela, pois o casamento era decidido pelo pai" (ARAÚJO, 2008, p. 51).

A escolha dos noivos era norteada pelo princípio básico da igualdade, que deveria se estabelecer nos níveis etário, social, físico e moral. A questão da igualdade de idades era comumente desrespeitada haja vista, os inúmeros casos de meninas de 12 a 15 anos que se casavam com homens de 30 a 50 anos. Dentre os princípios apresentados o mais importante era o social, ou seja, a posição que o cônjuge ocupava na sociedade e as condições econômicas que este dispunha, afinal o casamento era uma espécie de negócio.

Conforme menciona Del Priore (2005, p. 17): “[...] negócios grandes, grandes conselhos requerem. [...] (a mulher não se deve escolher por gosto); não seja o amor [...] seja antes a razão que nos dirija nesse negócio". O casamento de maneira geral no Brasil Colônia se constituía numa instituição básica para a transmissão do patrimônio, pois impedia a dispersão de fortunas acumuladas. Para a mulher, porém, era um mecanismo disciplinador que a tornaria um modelo de virtude.

$\mathrm{O}$ casamento implicaria à mulher, dependência e sujeição ao marido. A mulher deveria ser a esposa e não a amante, deveria amar e respeitar o seu marido na forma do amor conjugal, um amor casto e virtuoso, no qual a mulher era a companheira do homem. A mulher como já mencionada, deveria ser virtuosa e honrada, estas eram características ideais para uma boa esposa.

Durante todo o Brasil Colonial constata-se que as relações sociais estavam regidas por uma ideologia de superioridade masculina, alicerce do patriarcalismo. Essa ideologia tem raízes antigas e por isso difícil de serem rompidas, de tal forma que ainda na contemporaneidade é possível observar-se traços do patriarcalismo. O apóstolo Paulo já exortava na sua Carta aos Efésios, Bíblia (1992), que: 
As mulheres sejam submissas a seus maridos, como ao senhor, pois o marido é o chefe da mulher, como Cristo é o chefe da igreja [...] Ora, assim como a Igreja é submissa a Cristo, assim também sejam em tudo as mulheres a seus maridos. (Ef 5, 25-26).

Baseada nos escritos de Paulo e posteriormente nos de Santo Agostinho entre outros autores, a tradição católica foi se constituindo de maneira a conferir um papel de superioridade ao homem e de submissão a mulher. Durante a Idade Média na Europa este padrão de vida se consolidou, tomou forma e força. O mesmo padrão foi trazido para o Brasil pelos colonizadores. O patriarcalismo sacramentou na Europa e no Brasil o homem como chefe absoluto da família.

Desde o século XV com a publicação do Malleus maleficarum ( $O$ martelo das feiticeiras), escrito por frades dominicanos alemães, os sacerdotes eram orientados a vigiar e punir mulheres que praticassem feitiçaria (LOPES, 2003). Os sacerdotes acreditavam que os feitiços e porções fabricados pelas bruxas eram utilizados principalmente no campo afetivo, nesse sentido até uma atração que uma determinada mulher pudesse despertar em um homem era entendida pela Igreja $\mathrm{Ca}$ tólica como uma manifestação maléfica própria da mulher em querer desvirtuar o homem, uma excitação aos pecados da carne.

A Igreja Católica atribuía ao sexo somente função procriativa, sendo condenadas carícias entre os cônjuges ou quaisquer outros artifícios que despertassem os prazeres da carne. Sempre que solicitada pelo marido a mulher deveria pagar o débito conjugal, ou seja, ter relações sexuais, é claro com fins reprodutivos. O catolicismo buscava disciplinar os fiéis no tangente a sexualidade conforme nos relata Souza Filho (2004):

A Igreja com seu rigorismo moral oficial se utilizou de muitos mecanismos com vistas a controlar a sexualidade quais sejam: o medo, a condenação ao inferno, o juízo final, todavia o mais eficaz de todos foi a Confissão, que obrigava o povo a detalhar os desejos e práticas sexuais ao mesmo tempo se servia do discurso dos penitentes para reprimi-los. (FILHO, 2004, p. 35)

Outro mecanismo de controle sobre a mulher foi à educação que era totalmente diferenciada da educação do homem, pois a educação feminina estava relacionada com os afazeres domésticos, enquanto a 
do homem era direcionada a vida social fora do lar. A menina aprendia tudo o que era necessário para o bom funcionamento de seu futuro lar, era importante que ela estivesse preparada com o mínimo de educação formal, o que se pressupõe para tal saber ler, escrever, contar, coser, cozinhar e bordar. Freyre (2006, p. 510) assim nos retrata: “À menina, à esta negou-se tudo que de leve parecesse independência. Até levantar a voz na presença dos mais velhos. Tinha-se horror e castigava-se a beliscão a menina respondona e saliente, adoravam-se as acanhadas, de ar humilde".

Embora a Igreja Católica pretendesse controlar a vida sexual dos colonos muitos fatores contribuíam para que existissem na colônia relacionamentos amorosos diferentes dos preceituados pela Igreja, facilitado pelo pouco número de igrejas e clérigos, o que dificultava a fiscalização da moral naquela época. Além disso, o patriarcalismo vigente conferia muitos poderes aos senhores de engenho fazendo com que estes muitas vezes descumprissem os preceitos da Igreja. Um dos últimos fatores a serem observados era a diversificada composição populacional da colônia, haviam muitos negros e índios com costumes e tradições próprios que muitas vezes divergiam dos costumes europeus. Havia também degredados de moral duvidosa. A estes juntavam-se os brancos europeus que estavam longe do forte controle do Estado e da Igreja imposto na Europa.

Concubinato ou relações consensuais eram mais comuns do que casamentos, apesar das fortes censuras impostas pelo catolicismo que muitas vezes resultavam em excomunhões e prisões.

Nessa época apenas membros das classes subalternas conseguiam escolher seus cônjuges de forma mais espontânea. Tal como os camponeses europeus, os pobres da colônia não tinham interesses político-econômicos para preservar e por isso podiam deixar aflorar os sentimentos, Nos concubinatos tão disseminados [...] encontram-se gestos amorosos e expressões de afeto bastante discretos no mais do cotidiano. (DEL PRIORE, 2005, p.26).

Quando os portugueses chegaram ao Brasil, ficaram surpreendidos com o modo de viver dos índios, principalmente com o fato deles andarem nus. As índias peladas conseguiam despertar os desejos carnais dos homens brancos, esses desejos logo puderam ser saciados na medida 
em que Portugal implementava a sua colônia o modelo de produção escravista que dava plenos poderes aos senhores sobre suas escravas.

A escravidão indígena rapidamente foi substituída pela escravidão africana, pois esta oferecia mais lucros à coroa portuguesa enquanto aquela favorecia apenas a colônia. Os negros eram trazidos da África para o Brasil em navios superlotados sem o mínimo de higiene, eram tratados como animais, sujeitando-se às ordens dos seus senhores.

[...] Pelas leis antigas a escrava era considerada uma coisa, podendo ser vendida, dada, alugada, como se fazia com as bestas. Aliás, a legislação dizia: os escravos e as bestas poderão ser vendidos [...]. Só depois de, ou quando era libertada ao nascer (Lei do Ventre Livre) é que a escrava poderia ter um sobrenome, o do antigo senhor se esse o permitisse, ou ligado a algum santo ou referência religiosa [...]. (FALCI, 2008, p. 255).

No período colonial as negras foram responsabilizadas pela iniciação sexual dos filhos dos senhores. Na verdade, as primeiras relações dos sinhozinhos eram mantidas com os meninos negros que eram postos para brincar com os brancos, e também com animais domésticos e plantas como a bananeira e a fruta do mandacaru. Além disso, "o que a negra da senzala fez foi facilitar a depravação com a sua docilidade de escrava; abrindo as pernas ao primeiro desejo do sinhô-moço. Desejo, não: ordem" (FREYRE, 2006, p. 456).

As mulheres negras eram tratadas como objetos sexuais dos seus senhores e dos filhos destes. Por canto das traições de seus maridos com as escravas, muitas sinhás castigavam severamente as amantes negras. Dentre os castigos mais comuns as negras tinham os seios cortados, ou as arcadas dentárias retiradas.

\subsection{A Mulher Brasileira na Sociedade Burguesa}

O modelo de família patriarcal perdurou durante todo o período Colonial, perpassando também pelo Brasil Imperial. Apenas no século XIX como o surgimento de uma nova mentalidade, a burguesa, pode-se perceber a construção de novos valores sociais, que reestruturam a família e redefinem o papel que a mulher deverá desempenhar. Embora o patriarcalismo tenha sido base da sociedade colonial seus resquícios ainda poderão ser observados mesmo durante o século XIX e até mesmo 
nos dias atuais, certamente com algumas adaptações, mas a ideia central permanece, o homem como chefe absoluto da família.

Importantes transformações sociais começaram a acontecer no Brasil desde a fuga da Família Real de Portugal, fazendo da então Colônia como sede da Coroa Portuguesa. Essa transferência trouxe uma intensificação das atividades econômicas com a abertura dos portos às nações amigas, além disso ocorreram grandes avanços culturais e educacionais, com a criação de universidades, e da Biblioteca e Museu Real entre outros. Esses fatores acabaram por incrementar a vida social da colônia. Entretanto como assinala D'Incao (2008) foi a partir da segunda metade do século XIX nos últimos anos do Império e com a Proclamação da República que a burguesia brasileira, antigos cafeicultores principalmente, instauraram novos hábitos e costumes mais condizentes com o recente processo de urbanização e modernização.

De acordo com Del Priore (2005) a organização física das casas no início da sociedade burguesa no Brasil constitui-se em fator fundamental na mudança das relações sociais dentro da família, afetando a rotina do casal. Nesse sentido, no começo do século XIX as cidades não tinham organização, as ruas se desenhavam de acordo com a disposição das casas e não havia regras para a sua ocupação. As janelas e portas das casas abriam-se diretamente nas ruas. O processo de modernização trouxe uma valorização do espaço público. Assim, as ruas passaram a ter uma maior ordenação e calçadas para que ficassem separadas das casas.

Essas mudanças externas influenciaram na organização interna das casas tornando-as mais aconchegantes. A intimidada passou a ser valorizada, de tal modo que um quarto já não se conectava com outro através de portas que formavam corredores internos, agora o quarto do casal era isolado dos filhos e outros familiares também se possível. $\mathrm{Na}$ verdade, a família não era mais tão grande como as do período colonial e não haviam escravos rondando a casa, pois com a abolição passou a existir os serviçais assalariados que podiam ou não morar com o patrão.

Ainda segundo Del Priore (2005) embora com privacidade, as casas burguesas também reservavam espaços para um convívio social mais amplo, eram os salões onde se davam festas e jantares e, a mulher tinha que estar preparada para ao lado de seu marido receber convidados. Além disso, com a urbanização, a mulher passou a frequentar 
cafés, bailes, teatros e para tal tinha que aprender a se portar. Se no período colonial a mulher tinha uma vida restrita ao lar sendo julgada apenas pelos seus familiares, agora estava sob a vigilância constante da sociedade.

A vida social ativa faz com a mulher passe a ser educada para se comportar nos lugares públicos. A postura que esta estabelece nas relações sociais é determinante para a manutenção do status do marido e da família. Assim sendo a mulher tinha que ser uma anfitriã educada, uma esposa dedicada e uma mãe carinhosa. Segundo D'Incao (2008):

[...] num certo sentido, os homens eram bastante dependentes da imagem que suas mulheres pudessem traduzir para o restante de pessoas de seu grupo de convívio. Em outras palavras, significavam um capital simbólico importante, embora a autoridade familiar se mantivesse em mão masculinas, do pai ou do marido. Esposas, tias, filhas, irmãs, sobrinhas (e serviçais) cuidavam da imagem do homem público; esse homem aparentemente autônomo, envolto em questões de política e economia, estava na verdade rodeado por um conjunto de mulheres das quais esperava que o ajudassem a manter sua posição social. (D’INCAO, 2008, pp. 228-229)

O casamento neste período continua sendo uma forma de manter o nível social ou elevá-lo. Com a intensificação da vida social, os casamentos, embora muitas vezes arranjados, passam a permitir que os noivos se conheçam antes, nos sarais e festas, por isso mesmo era importante que as mulheres se apresentassem bem nesses espaços públicos. Embora namoros fossem proibidos, sempre haviam trocas de olhares ou juras românticas, nesses momentos podiam-se escolher os pretendentes a matrimônio, que só deveria ser acertado entre os pais.

De acordo com Del Priore (2005) e D'Incao (2008) outro componente também irá adocicar os relacionamentos das famílias burguesas, é a ascensão do amor romântico, agora os sentimentos encontram espaço e o amor ganha lugar privilegiado. As leituras das novelas em folhetins e livros acabam por inspirar nos corações das jovens, o ideal de amor com estado de espírito distante daquele ligado a atrações físicas.

Amor... Ama-se por que todo o período romântico ama. Ama-se o amor e não propriamente as pessoas. Apaixona-se, por exemplo, por uma moça que seria dona de um pezinho que, por sua vez, seria o dono do sapato 
encontrado. [...] ama-se então um conjunto de ideias sobre o amor. (DEL PRIORE, 2005, pp. 214-215).

Havia-se então de se encontrar no casamento, na intimidade do casal, o afloramento dos sentimentos, sejam esses de carinho ou de dor. A literatura da época trazia heróis e heroínas apaixonadas, mas não capazes de fazer loucuras por amor, afinal esse tipo de situação era evitada na classe burguesa. O amor deveria ser puro e casto, dentro da moral. São assim os romances de Joaquim Manoel de Macedo e parte a literatura de José de Alencar.

Além disso, para D'Incao (2008) a literatura nos mostra outra importante faceta do século XIX que também fora observado dos séculos anteriores no Brasil, aqueles de poucas posses muitas vezes conseguiam realizar casamentos guiados pelo afeto, as mulheres pobres e livres de interesses econômicos e políticos tinham mais liberdade para se apaixonar. O romance "Memórias de um sargento de milícias", de Manuel Antônio de Almeida, retrata a intensidade de carícias existentes entre os enamorados de classes subalternas. É importante ressaltar que antes do casamento as carícias permitidas eram apenas um leve tocar de mãos, ou para os mais ousados alguns beliscões.

O século XIX vai sublimar no imaginário social brasileiro papeis sociais fixos para homem e mulher. $\mathrm{O}$ homem consagrasse como o provedor da casa aquele que é responsável pelo sustento da família, é um trabalhador incansável para promover o bem-estar de todos. A mulher deve se entregar totalmente ao amor do marido e dos filhos, ela é esposa e mãe acima de tudo. O papel de mãe é tão valorizado que diferente do período colonial no qual os filhos eram entregues a amas de leite e depois a preceptores, passa-se a preferir que a primeira educação seja orientada pela mãe. Embora apontemos o século XIX como período de consolidação dessa diferenciação sexista, vale lembrar que esse ideal encontra bases do patriarcalismo.

A sociedade burguesa instaurou o modelo de produção capitalista aos poucos e este modelo de produção interferiu em todos os setores da sociedade, influenciando na cultura, na educação e na família entre outros campos. Com o apogeu da doutrina liberal o mudo pôde vivenciar a naturalização de muitas mazelas como a pobreza. O modelo de 
família monogâmica, centrada no homem com o provedor da casa e na mulher como organizadora do lar, próprio das elites, também foi sendo incorporado às demais classes sociais. Para as famílias pobres e do campo, o casamento monogâmico preserva os poucos bens que a família possui, o homem responsável pelo sustento da casa e a mulher cuida da casa e dos filhos, que não são poucos.

Mesmo com muitos reflexos colonialistas a família burguesa do século XIX acaba por propiciar a mulher uma maior importância social, se antes tinha uma vida de reclusão agora passa a frequentar ambientes variados. A mulher também passa a ter um contato mais intenso com a literatura, a cultura e informação de maneira geral. Estes fatores possibilitaram uma maior efervescência de ideias que no século XX colaborarão para uma maior emancipação feminina. Ressaltando que toda essa "liberdade" tinha limites que eram observados por todos.

\subsection{Século XX e XXI e a Emancipação Feminina}

Para o Brasil e o mundo o século XX representa um período de grandes conquistas para a luta feminina. No Brasil o processo de industrialização iniciada no século XIX foi bastante incrementado no século seguinte, sendo que em suas primeiras décadas a maior parte do proletariado era composta por mulheres e crianças. A longa jornada de trabalhos e baixos salários oprimiam homens e mulheres, mas sobre estas havia um fardo ainda maior, pois muitas além do labor fabril ainda tinham que se dedicar aos trabalhos domésticos. Constantemente também as mulheres eram vítimas de abusos sexuais nas fábricas por parte de seus superiores.

Segundo Rago (2008), a ideia de ter mulheres nas fábricas não era tão bem aceita pela sociedade, apesar de elas serem a maioria. $\mathrm{Na}$ medida em que o processo industrial se torna mais atrativo aos homens, as mulheres vão sendo substituídas. Além disso havia outra barreira, a familiar, primeiramente os pais sempre preferiam um bom casamento a ter que ver a filha trabalhando, e segundo, muitas mulheres tinham que deixar o trabalho quando conseguiam um matrimônio, pois deveriam se dedicar a família. Rago (2008) nos aponta também que para médicos higienistas, juristas, jornalistas, as fábricas seriam um fator que con- 
tribuiriam para o desvio moral das mulheres, pois estes acreditavam juntamente com economistas europeus que:

O trabalho da mulher fora de casa destruiria a família, tornaria os laços familiares mais frouxos e debilitaria a raça, pois as crianças cresceriam mais soltas, sem a constante vigilância das mães. As mulheres deixariam de ser mães dedicadas e esposas carinhosas, se trabalhassem fora do lar; além do que um bom número delas deixaria de se interessar pelo casamento e pela maternidade. (RAGO, 2008, p. 585)

É evidente o interesse da elite intelectual e econômica da época na manutenção do status quo alicerçado no patriarcalismo colonial e legitimado como ideal de família para a burguesia. A mulher deve ser a boa esposa e mãe e não aquela que trabalha fora do lar, este papel foi destinado ao homem, o provedor do lar. Todavia para as mulheres de classes baixas e as que não conseguiam um bom casamento o trabalho era uma maneira de conseguir o sustento, mesmo que com isso tenham que se submeter a condições insalubres, abusos de patrões, a olhares maldosos da sociedade.

Afirmar que o trabalho fabril feminino iria acabar com a família, de fato é um exagero inconsistente, mas a verdade é que foi nas fabricas que as mulheres tiveram o primeiro contato com as ideias socialistas e anarquistas trazidas com os proletários europeus. No percorrer do século $\mathrm{XX}$ as mulheres travaram verdadeiras batalhas reivindicado igualdade de direitos entre homens e mulheres, condições dignas de trabalhos, direito ao voto e o acesso à educação de qualidade.

Todas essas mudanças puderam ser conquistadas paulatinamente, por que a sociedade como um todo se modernizava, principalmente pela chegada de estrangeiros para o trabalho nas fábricas e pelo incremento da cultura de modo geral. O cinema trazia as ideias norte-americanas, bibliotecas e teatros também se popularizavam e as mulheres, é claro, participavam destes espaços. Assim nos fala Bassanezi (2008) sobre meados do século XX:

O Brasil dos anos 50 viveu um período de ascensão de classe média. Com o fim da segunda Guerra Mundial, o país assistiu otimista e esperançoso ao crescimento urbano e à industrialização sem precedentes que conduziram ao aumento das possibilidades educacionais e profissionais 
para homens e mulheres. Democracia e participação eram ideias fortalecidas nos discursos políticos. Em geral ampliaram-se aos brasileiros as possibilidades de acesso à informação, lazer e consumo. (BASSANEZI, 2008, p. 608)

Embora tenha ocorrido no século XX a proliferação de ideias revolucionárias e uma crescente modernização industrial e cultural a inserção das mulheres ao mercado de trabalho e a garantia de seus direitos não foi conquistada sem contestações, como já havíamos ditos anteriormente, muitos setores da sociedade não concordavam com esta situação, como muitos profissionais liberais, a igreja, e até mesmo muitos operários anarquistas ou socialistas. Como menciona Rago (2008) o positivismo, importante corrente ideológica no século XX, seguia os ensinamentos de Augusto Comte e postulava que:

A mulher não deveria possuir dinheiro - um objeto sujo, degradante e essencialmente masculino, portanto contrário à sua natureza. A mulher deveria se restringir ao seu "espaço natural", o lar, evitando toda sorte de contato e atividade que pudesse atraí-la ao mundo público. (RAGO, 2008, p. 592)

Superando obstáculos, as mulheres divididas em três correntes de pensamento, o socialismo, o comunismo e o anarquismo, reivindicavam de maneira geral a existência de uma sociedade justa e igualitária. Em primeiro lugar não estavam os direitos das mulheres, mas sim os direitos de todos, sem distinção de raça, idade, sexo ou classe socioeconômica. Haviam de certa forma uma valorização do coletivo em detrimento dos interesses individuais como propõem o capitalismo. Nesse contexto, no qual a coletividade fosse valorizada, as mulheres teriam seus direitos garantidos naturalmente.

Mesmo a luta feminista estando em segundo plano, as operárias sempre colocavam em pauta nas reuniões e assembleias, a questão da conquista dos direitos femininos. Da mesma forma, elas organizavam jornais e folhetins que tratavam especificadamente da luta feminina. Além disso, elas faziam passeatas próprias em busca de seus direitos. É preciso compreender que a luta feminista em um contexto socialista, anarquista ou comunista não estava em segundo plano por questão de 
demérito, mas sim por que na sociedade em que se deseja construir, elas estariam lado a lado naturalmente.

Em meados do século XX já era possível se observar muitas conquistas femininas, já era permitido às mulheres certa qualificação profissional, muitas terminavam o ensino médio nas escolas normais, desenvolvendo assim a carreira de professoras, outras faziam cursos de datilografia e podiam ser secretárias em empresas. Às mulheres era permitido somente trabalho em postos de submissão aos homens, muitas ainda recebiam salários baixos, fato este que persiste na atualidade, embora com mudanças.

As últimas três décadas do século XX e esta primeira década do século XXI representam, de maneira especial, a conquista de direitos das mulheres, não por acaso, é neste mesmo período que as democracias se apresentam como o modelo de governo a ser firmado por todas as nações. A democracia traz consigo o ideal de "igualdade" na qual homens e mulheres independente de raça, cor, religião ou posição social, compartilham dos mesmos direitos.

No Brasil após o fim da ditadura na década de 1980 foi que as mulheres conseguiram exercer o direito ao voto de maneira plena, embora ele tenha sido conquistado em 1934, somente nas últimas décadas do século passado foi possível assistir à massificação do voto feminino. Outra importante conquista aconteceu no século XXI em 2003 no governo de Luiz Inácio Lula da Silva, a criação da Secretaria de Políticas para as Mulheres com o objetivo de construir políticas públicas voltadas para mulheres. Um claro resultado alcançado pela Secretaria em conjunto com estruturas da sociedade civil organizada foi a Lei Maria da Penha que cria mecanismos para proteger a mulher da violência doméstica.

Hoje, existem mulheres que seguem carreira profissional e dedicam-se ao lar ao mesmo tempo, outras que para ter um maior cuidado com filhos, não se profissionalizam. Existem ainda mulheres que preferem ter filhos e se casar após os 30 anos ou quando possuem uma boa estabilidade financeira e profissional e outras se quer desejam ter filhos. Entre tantas mulheres, todas encontram virtudes que as diferenciam das outras e, essa mulher de hoje traz consigo um autêntico alicerce de lutas, amores e desamores que sustenta como de fato deve ser vista a noção da mulher brasileira. 


\section{Considerações Finais}

Acreditamos que todo o exposto consegue responder a nossa inquietude em entender de qual maneira a noção de mulher foi construída pelo imaginário social brasileiro.

Vimos que para a sociedade patriarcalista do Brasil Colônia, na qual o homem exercia o papel de senhor absoluto, tanto as mulheres brancas, quanto as pardas e as negras não eram diferentes, todas estavam à mercê das ordens, imposições e da autoridade de seus senhores. A mulher foi permanentemente controlada em sua sexualidade sendo vista como elemento de desvio moral para os homens. Mesmo considerada como vilãs, as mulheres foram vítimas da repressão imposta pela sociedade da época.

Vimos ainda que, embora a diferenciação homem/mulher tenha raízes no patriarcado colonial, a burguesia produziu novas facetas para cada um dos sexos, sacramentado a oposição homem (trabalhador, destinado a vida pública) e mulher (mãe e dona de casa, destinada a vida doméstica).

O século XXI é marcado pelo pluralismo de concepções sobre as mulheres, se nos outros séculos já era difícil defini-las em torno de características comuns, agora elas podem escolher tantos destinos que fica impossível uma singularização, o que faz com que emerjam mulheres conscientes de seus direitos e autoras de suas próprias histórias, se assumindo de forma igual nos mais distintos contextos sociais.

\section{Referências}

ARAÚJO, Emanuel. A arte da sedução: sexualidade feminina na Colônia. In: DEL PRIORE, Mary (Org.). História das mulheres no Brasil. 9. ed. São Paulo: Contexto, 2008.

BASSANEZI, Carla. Mulheres dos anos dourado. In: DEL PRIORE, Mary (Org.). História das mulheres no Brasil. 9. ed. São Paulo: Contexto, 2008. BÍBLIA. Português. Bíblia de Referência Thompson. Tradução de João Ferreira de Almeida. Edição rev. e corr. Compilado e redigido por Frank Charles Thompson. São Paulo: Vida, 1992.

DEL PRIORE, Mary. História do amor no Brasil. São Paulo: Contexto, 2005. 
D'INCAO, Maria Ângela. Mulher e família burguesa. In: DEL PRIORE, Mary (Org.). História das mulheres no Brasil. 9. ed. São Paulo: Contexto, 2008.

FALCI, Miridan Knox. Mulheres do sertão nordestino. In: DEL PRIORE, Mary (Org.). História das mulheres no Brasil. 9. ed. São Paulo: Contexto, 2008.

FREYRE, Gilberto. Casa-grande e senzala: formação da família brasileira sob o regime da economia patriarcal. 51. ed. São Paulo: Global, 2006.

LOPES, Rita de Cássia. Bruxas, feiticeiras e curandeiras: a mulher na inquisição. Revista Mundo e Missão, São Paulo, ano 10, n. 70, p. 22-24, mar. 2003. RAGO, Margarethe. Trabalho feminino e sexualidade. In: DEL PRIORE, Mary (Org.). História das mulheres no Brasil. 9. ed. São Paulo: Contexto, 2008. 